\title{
Edible fruit extracts and fruit juices as potential source of antiviral agents: a review
}

\author{
Veerasamy Pushparaj Santhi ${ }^{1} \cdot$ Venkatraman Sriramavaratharajan $^{2} \cdot$ Ramar Murugan $^{3} \cdot$ Poomaruthai Masilamani $^{1,4}$. \\ Shailendra S. Gurav ${ }^{5} \cdot$ Veerasamy Pushparaj Sarasu ${ }^{6} \cdot$ Subbaiyan Parthiban $^{1} \cdot$ Muniappan Ayyanar $^{7}$ (1)
}

Received: 30 March 2021 / Accepted: 28 July 2021 / Published online: 3 August 2021

(c) The Author(s), under exclusive licence to Springer Science+Business Media, LLC, part of Springer Nature 2021

\begin{abstract}
Fruits have been widely consumed since the beginning of human evolution and are important source of a healthy being and helpful in treating various diseases as immunity boosters with the presence of a rich amount of health-promoting bioactives. Therapeutic efficacies of fruit extracts are reported to have immune-modulatory properties and influence greatly on the immune system of human body. Given the facts of the efficacy of edible fruits in improving the immunity of body as immunestimulants, we have tried to consolidate the previously published data on edible fruits and its juices with antiviral potential. The objective of this review was to gather information on edible fruits with antiviral properties and the efforts to obtain their efficient delivery. Online bibliographical databases like PubMed, Scopus, and Web of Science were used to search literature on the antiviral effect of edible fruit extracts and fruit juices. The edible fruits like almond, apple, bael, blackberry, black currants, crane berry, citrus, grapes, Japanese cherry, mango, mulberry, pistachios, pomegranate, and strawberry showed promising antiviral properties against the different pathogenic viruses. The review provided an overview of likely effects of the intake of edible fruit extracts/fruit juices to strengthen the immune cells by reducing the oxidative stress in host body system which in turn inhibits the viral attachment and replication on the host cell. Hence these fruits can also be exploited in combating COVID-19 in the current pandemic situation. To validate the present hypothesis, the proposed edible fruit extracts can be evaluated against the SARS-CoV-2 via in vitro and in vivo models to confirm the fact.
\end{abstract}

Keywords Bioactive compounds · COVID-19 $\cdot$ Edible fruits $\cdot$ Fruit juices $\cdot$ Immunomodulators $\cdot$ Natural pigments $\cdot$ Viral replication

$\begin{array}{llll}\text { Abbreviations } & \text { HAV } & \text { Hepatitis A virus } \\ \text { ADV } & \text { Adeno virus } & \text { HCV } & \text { Hepatitis C virus } \\ \text { CHIKV } & \text { Chikungunya virus } & \text { HIV } & \text { Human immunodeficiency virus } \\ \text { CV-B1 } & \text { Coxsackievirus B1 } & \text { HSV-1 } & \text { Herpes simplex virus-1 } \\ \text { CV-B3 } & \text { Coxsackievirus B3 } & \text { HSV-2 } & \text { Herpes simplex virus-2 } \\ \text { CV-B5 } & \text { Coxsackievirus B5 } & \text { IFN- } \alpha & \text { Interferon alpha } \\ \text { DENV } & \text { Dengue virus } & \text { IFN- } \gamma & \text { Interferon gamma } \\ \text { FCV } & \text { Feline calicivirus } & \text { IFV-A } & \text { Influenza A virus }\end{array}$

Muniappan Ayyanar

asmayyanar@yahoo.com

1 Department of Fruit Science, Horticultural College and Research Institute for Women, Tamil Nadu Agricultural University, Tiruchirappalli, India

2 Virchow Biotech Private Limited, Survey No.172 part, Gagillapur, Hyderabad, India

3 Centre for Research and Postgraduate Studies in Botany, Ayya Nadar Janaki Ammal College (Autonomous), Sivakasi, India
4 Anbil Dharmalingam Agricultural College and Research Institute, Tamil Nadu Agricultural University, Tiruchirappalli, India

5 Department of Pharmacognosy, Goa College of Pharmacy, Goa University, Panaji, India

6 Department of Clinical Microbiology, Government Medical College, Pudukkottai, India

7 Department of Botany, A.V.V.M. Sri Pushpam College (Autonomous), Bharathidasan University, Poondi, Thanjavur, India 


$\begin{array}{ll}\text { IFV-B } & \text { Influenza B virus } \\ \text { IL-12 } & \text { Interleukin 12 } \\ \text { MDCK } & \text { Madin-Darby canine kidney } \\ \text { MNV } & \text { Murine norovirus } \\ \text { MS2 } & \text { MS2 bacteriophage } \\ \text { PBMC } & \text { Peripheral blood mononuclear cell } \\ \text { PEDV } & \text { Porcine epidemic diarrhea virus } \\ \text { RNS } & \text { Reactive nitrogen species } \\ \text { ROS } & \text { Reactive oxygen species } \\ \text { RSV } & \text { Respiratory syncytial virus } \\ \text { SARS } & \text { Severe acute respiratory syndrome } \\ \text { Th1 } & \text { T helper type 1 } \\ \text { Th2 } & \text { T helper type 2 } \\ \text { TNF- } \alpha & \text { Tumor necrosis factor alpha } \\ \text { VZV } & \text { Varicella-zoster virus }\end{array}$

\section{Introduction}

Fruits have been widely consumed since the beginning of human evolution and are important source of a healthy being with rich in minerals, water content, carbohydrates, fiber, protein, and a rich amount of health-promoting bioactives. Apart from the nutritional features, fruits have also been extensively studied for a wide range of pharmacological activities [1]. Therapeutic efficacies of plant extracts (especially fruits) are reported to have immune-modulatory properties and influence greatly on the immune system of human body [2]. Epidemiological, experimental, and clinical studies prove that intake of edible fruits reduces the risk of development of diseases associated with oxidative stress such as neurodegenerative disorders, cancer, diabetes, cardiovascular and related diseases [3].

Edible fruits are widely recommended as an important diet for nutritional and health-promoting properties due to the presence of vitamins, minerals, and most importantly antioxidant rich active molecules [4]. All parts of edible fruits like kernel, seeds, seed coats, fibers, and even fruit peels possess essential nutrients and reported to have widespread pharmacological properties [5]. The fruit peels obtained from lemon, grapes, oranges, avocado, jackfruits, longans, and mangoes also possess comparatively more amount of phenolic compounds than the fruit pulp of these plants [1].

Regular intake of fruit juice or fresh fruits is protective against several sicknesses including viral diseases. Though the extensive research on the mechanism of action of fruit juices in the prevention of various disease conditions is still one of the thrust areas of research in the last few decades [6]. The excess amount of free radicles produced in the body by many factors could cause oxidative stress which leads to chronic diseases, so the consumption of edible fruits with a rich amount of antioxidants in daily diet will prevent or slow down the oxidative stress [7].

To defence against numerous infectious diseases, the natural defence mechanism in the human body is organised by the body's immunity, followed by past infection, immunisation, and various external stimuli [8]. To boost the human body's defence mechanism, fruits are one of the perfect choices because it holds versatile active molecules which warrant numerous biological activities. Suárez et al. [9] reported that fruits rich in polyphenols had several health benefits and reduced risk of cardiovascular diseases, viral diseases, Alzheimer's disease, cancer, and diabetes. As plant-based pharmacotherapy is ideal for treating viral diseases, the edible fruits and their phytochemicals are extensively studied for antiviral properties. People in their dayto-day life consume a considerable amount of fruits which in turn exhibits antiviral properties and give immunity to combat various infectious diseases including viral diseases.

Given the facts of the efficacy of edible fruits in improving the immunity of body as immune-stimulants, we have tried to consolidate the previously published data on edible fruit extracts and their juices with antiviral potential. The objective of this review was to gather information on edible fruits with antiviral properties and efforts to obtain their efficient delivery. Since the edible fruits are reported to possess antiviral properties, these can also be utilized in combating COVID-19 in the current pandemic situation. The review also provided an overview of likely effects of the intake of edible fruits/fruit juices to strengthen the immune cells by reducing the oxidative stress in host body system which in turn inhibits the viral attachment and replication on the host cell.

The edible fruits with antiviral reports included in this review are almond, apple, bael, blackberry, black currants, crane berry, citrus, grapes, mango, mulberry, pomegranate, and strawberry which showed potential antiviral activities as given in Table 1 and Fig. 1. Several of these edible fruit extracts have potential antiviral effect by either inhibiting the formation of viral DNA/RNA or inhibiting the activity of viral reproduction inside the host cell.

\section{Review methodology}

The online bibliographical databases like PubMed, Scopus, and Web of Science were used to search literature on the antiviral effect of edible fruit extracts and fruit juices. The literature search was conducted with the key terms such as 'edible fruits', 'fruit extracts', edible fruit extracts, 'antiviral activity' along with 'fruit juices', 'viral infections', 'viral replication', 'immuno-modulators', and 'immune boosters'. The reports which published in English only considered and included while compiling this review. Also the articles which hold complete information regarding the proposed 


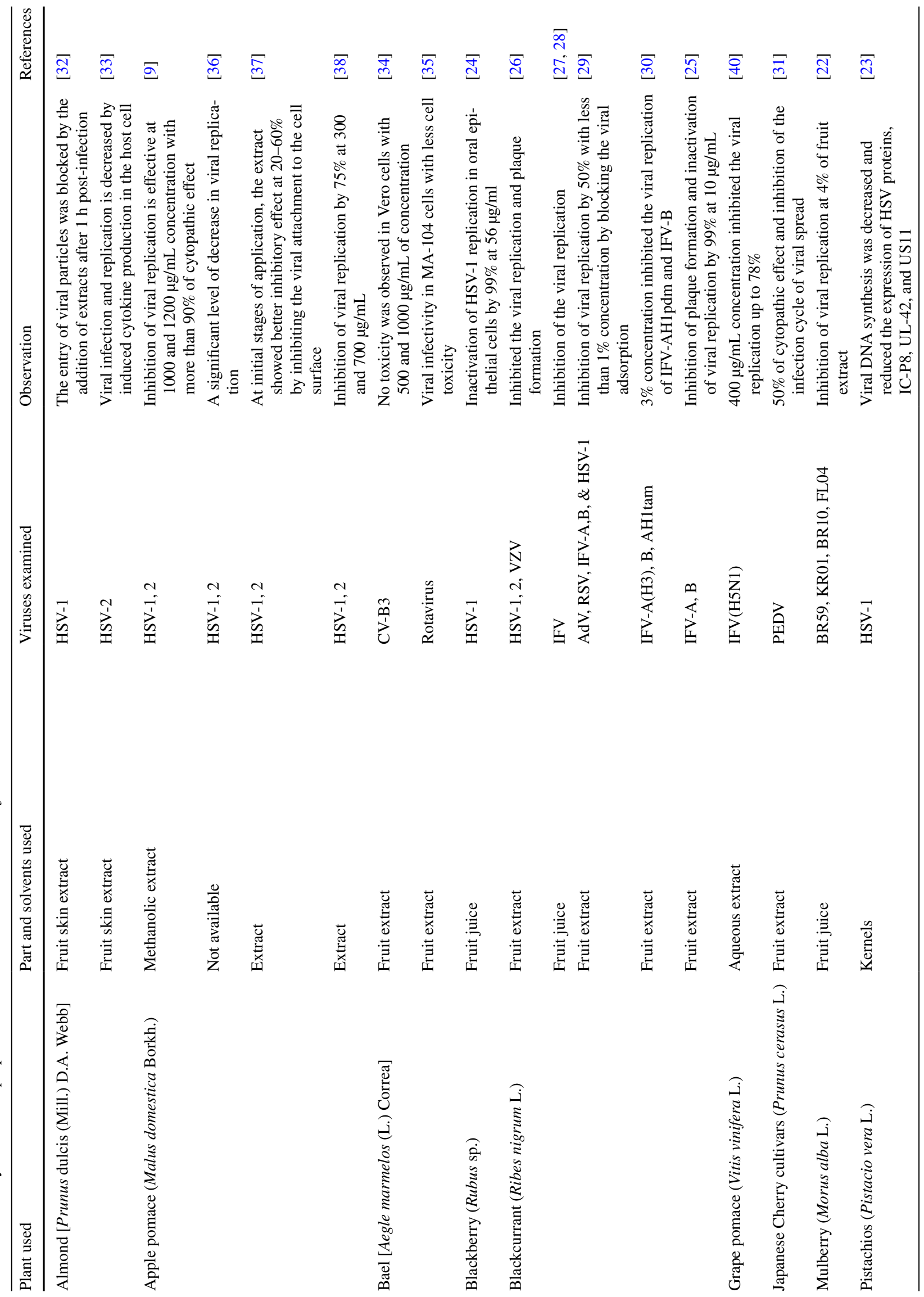




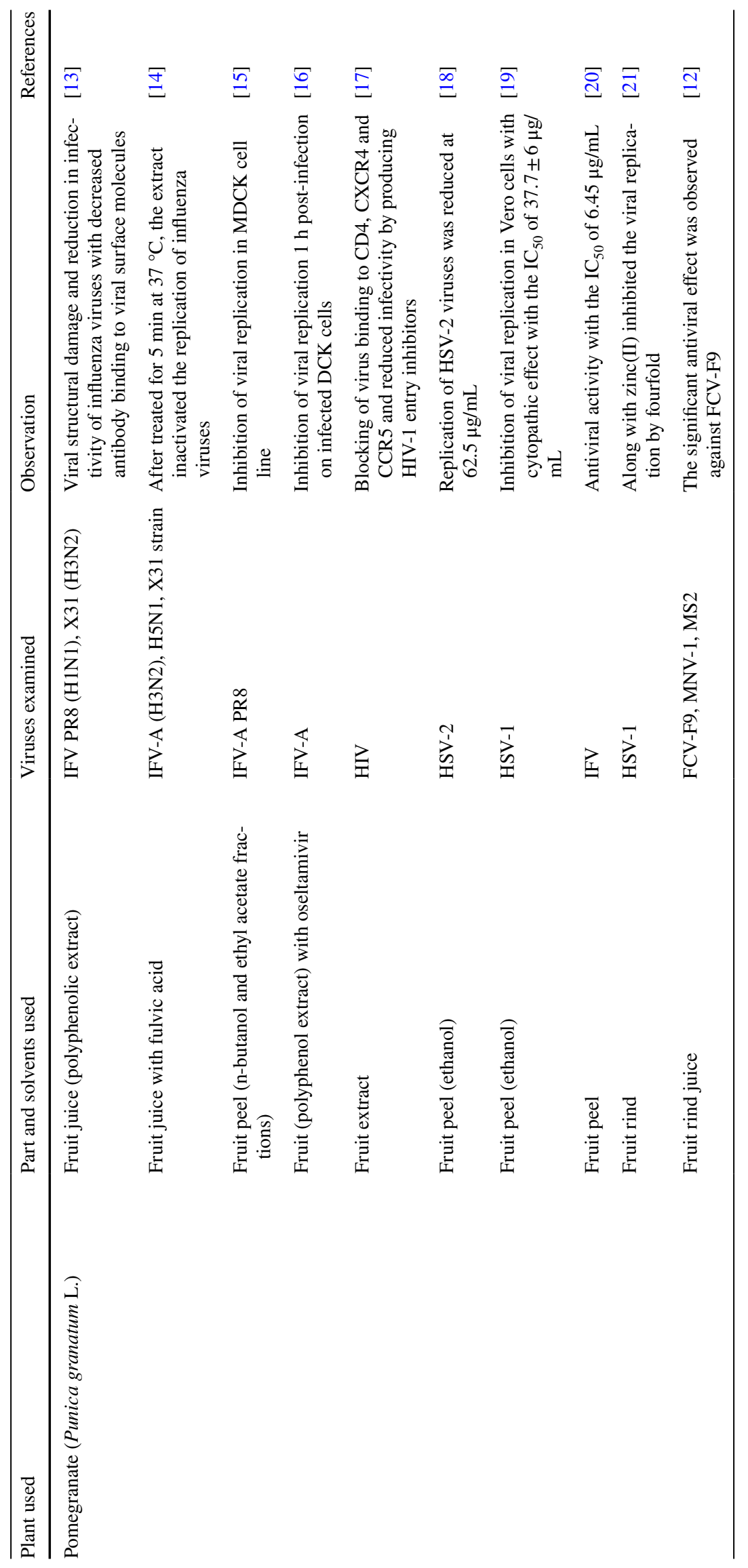


Fig. 1 Overall view of the antiviral effect of edible fruits and their constituents against the pathogenic viruses

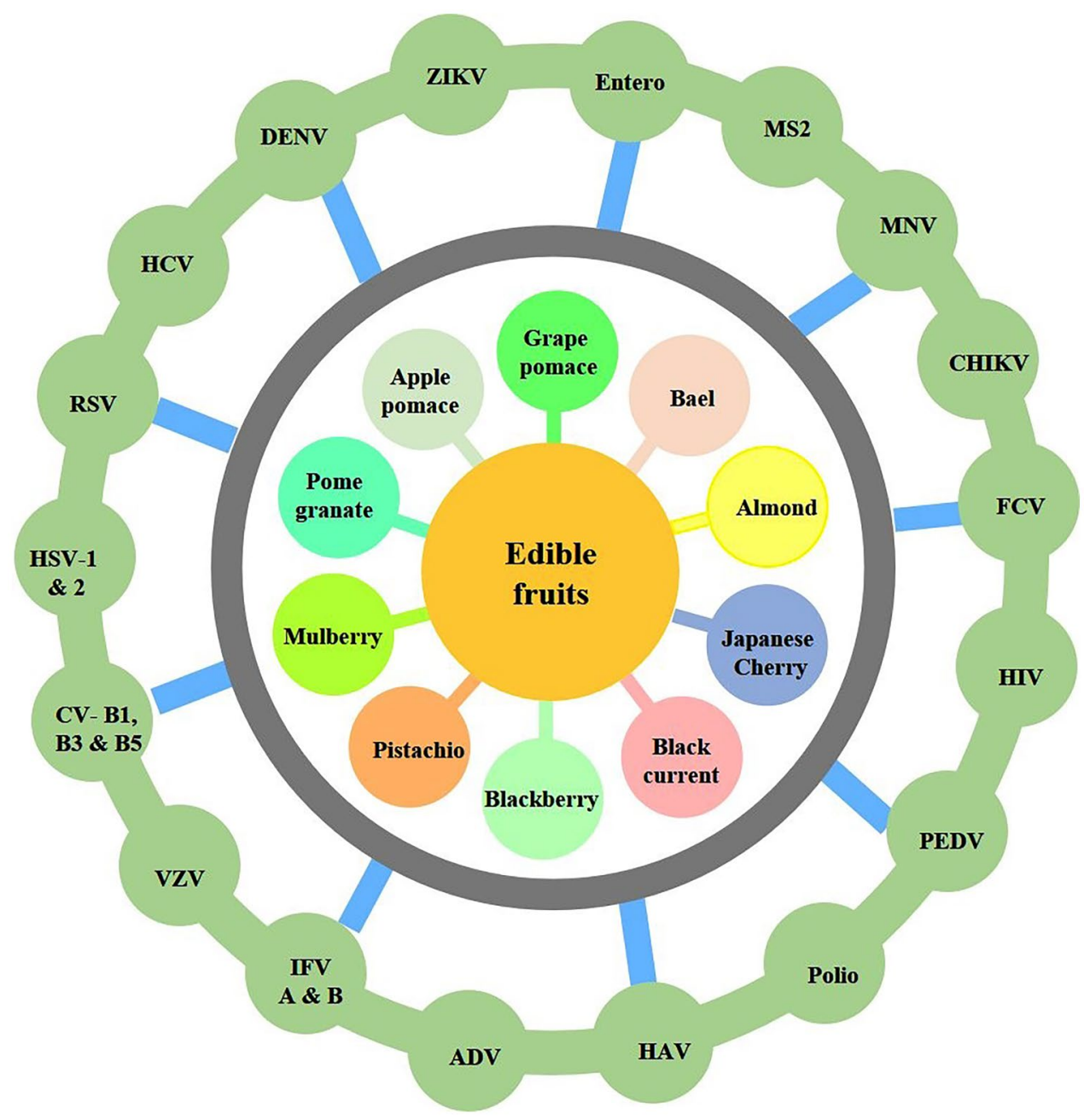

antiviral activity of edible fruits and fruit juices were considered. The references mentioned in the retrieved research and review articles were also explored to acquire complete results.

\section{Edible fruits as a source of antiviral agents}

\section{Pomegranate fruit against influenza, HSV-1, and HIV}

The fruits of pomegranate [Punica granatum L., Lythraceae] have been used in traditional systems of medicine throughout the world in treating various diseases including infectious diseases and upper respiratory tract infections, especially influenza [10]. Pomegranate juice is a potential candidate for inhibiting viruses that are transmitted through infected food products and bodily fluids [11]. Pomegranate fruit juice and polyphenols from the fruit rind showed significant antiviral activity against the foodborne viral surrogates like FCV-F9, MNV-1, and bacteriophage MS2 with decreasing low titers by $2.56,1.32$, and $0.32 \log _{10}$ PFU/mL respectively [12]. Of these, the potent antiviral effect was observed on FCV-F9 after treatment with 8,16 , and $32 \mathrm{mg} / \mathrm{mL}$ of polyphenolic extract. Pomegranate juice and concentrated liquid pomegranate extract showed antiviral activity against the influenza viruses, PR8 (H1N1), and X31 (H3N2) [13]. After the treatment with fruit extracts that contains polyphenolic compounds, loss of haemagglutinating activity was observed to accompany the reduction in infectivity of influenza viruses with decreased antibody binding to viral surface molecules which result in viral structural damage.

The pomegranate juice can neutralize the infectivity and effective against the different types of enveloped viruses like influenza A (H3N2), H5N1, and a reassortant X31 strain [14]. The pomegranate juice with fulvic acid showed an effective antiviral property by inactivating different strains of influenza viruses especially H5N1 after treated for 5 min at $37^{\circ} \mathrm{C}$. The n-butanol and ethyl acetate fractions attained from the pomegranate fruit peel extract effectively inhibited influenza A PR8 replication in the MDCK cell line with the $\mathrm{IC}_{50}$ of $6.45 \mu \mathrm{g} / \mathrm{mL}$ and viral titer was decreased in a dosedependent manner [15]. 
The MDCK cells treated with purified polyphenolic extract of pomegranate autonomously hampered the influenza A virus particle liberation onto media, $1 \mathrm{~h}$ post-infection and viral RNA titers significantly dropped down by the end of one growth cycle (9-12 h). This study signifies that polyphenolic extract of pomegranate hinders viral replication without relying on its virucidal effect [16]. Blocking the entry of viruses is a primary target in most of the antiviral studies for the microbicide development and pomegranate extract showed microbicidal effects on HIV-1 by producing HIV-1 entry inhibitors and the resulting complex blocks the virus binding to CD4 and CXCR4/CCR5 receptors and prevents the spread of infection [17]. The ethanolic extract of pomegranate peel shows significant inhibition at $62.5 \mu \mathrm{g} /$ $\mathrm{mL}$ against the HSV-2 and noticeably reduces the replication of HSV-2 after treating with the peel extract without any observed cytotoxicity [18].

The exposure of MDCK cells with the pomegranate fruit extract suppresses viral replication during the viral adsorption phase suggesting the viral entry inhibitory role of the fruit extract with potential virucidal capability. The combination of oseltamivir (an antiviral neuraminidase inhibitor) and pomegranate polyphenolic extract deliver appreciably improved inhibitory effect on infected DCK cells and it proves the synergistic effect in a concentration of $0.007 \mathrm{nM}$ for oseltamivir and $0.62 \mathrm{mg} / \mathrm{mL}$ for pomegranate extract [16].

Ethanolic pomegranate peel extract exhibits antiHSV- 1 activity with the $\mathrm{CC}_{50}$ and $\mathrm{IC}_{50}$ of $293.5 \pm 10 / 1$ and $37.7 \pm 6 / 7 \mu \mathrm{g} / \mathrm{mL}$, respectively and peel extract inhibits the replication in the adsorption stage in Vero cells [19]. Fruit peel extract also exhibits antiviral activity against the influenza viruses with an $\mathrm{IC}_{50}$ and $\mathrm{CC}_{50}$ of 6.45 and $55.66 \mu \mathrm{g} /$ $\mathrm{mL}$, respectively and this antiviral activity of pomegranate extract could be due to the presence of a high amount of hydrolyzable tannins and polyphenols chiefly punicalagin and gallagic acid [20].

The pomegranate fruit rind extract possesses significant antiviral against HSV-1 and exhibited much better progressive effect than the commercial antiviral compound acyclovir [21]. When the fruit rind extract co-administered with zinc (II), the mixture revealed strong antiviral activity against the acyclovir-resistant strain HSV-ACR with an $\mathrm{EC}_{50}$ of $0.016 \pm 0.009 \mu \mathrm{g} / \mathrm{mL}$ and that could be due to the presence of several chemical constituents present in the fruit rind extract.

\section{Mulberry fruit against DENV and HIV}

Mulberry [Morus alba L., Moraceae] fruit juice at 4\% concentration exhibits a meager effect against the influenza virus strains such as BR59, KR01, and BR10 and moderate activity against FL04 attaining $0.1-0.2$ and 0.4 $\log _{10}$ inhibition with the difference in pre-treatment (moderately effective) and post-treatment (less effective) [22]. The authors believe that the antiviral activity of mulberry juice is due to the presence of active chemicals like gallic acid which decreases the viral infection by inhibiting the internalization of the virus into the cells.

\section{Pistachio fruit against HSV-1}

Pistachio [Pistacio vera L., Anacardiaceae] kernel extracts effectively reduce the expression of HSV proteins (IC-P8, UL-42, and US11) and eventually decrease viral DNA synthesis [23]. The kernel extract with a rich amount of polyphenolic compounds shows a significant dose-dependent antiviral effect against HSV-1 with non-cytotoxic concentration. Also, the entire reduction in plaque formation suggests the immediate prevention of expression, transcription, and translation of viral proteins by the kernel extract after binding to the virus.

\section{Blackberry and blackcurrent fruits against HSV-1, IFV-A, B, AdV, and RSV}

Blackberry [Rubus sp., Rosaceae] fruit juice extract inhibits and inactivates HSV-1 replication in oral epithelial cells by $99 \%$ [24]. The researchers conclude the virucidal role of blackberry extract against HSV infections due to the presence of a rich amount of anthocyanins and ellagitannins. The blackcurrant [Ribes nigrum L., Grossulariaceae] fruit extract inhibits the plaque formation of both IFV-A and IFV-B at a concentration of $3.2 \mu \mathrm{g} / \mathrm{mL}$ by $50 \%$ and inactivates them up to $99 \%$ at $10 \mu \mathrm{g} / \mathrm{mL}$ [25]. Blackcurrant fruit also has a potential antiviral property against HSV and related infectious diseases that inhibit HSV-1 on cell membrane at a 100-fold dilution and plaque formation of HSV-1 and 2, VZV (Fig. 1) by 50\% at a 400 -fold dilution or even at lower concentrations [26]. It is also reported to have considerable antiviral activity against the influenza viruses and food-borne viral surrogates by inhibiting the viral replication in vitro [27, 28].

The blackcurrant extract at less than $1 \%$ concentration represses 50\% replication of RSV, IFV-A, IFV-B, and HSV-1 and $10 \%$ of extract evades $95 \%$ viral attachment from the cell. It has activity against Adenovirus with an $\mathrm{IC}_{50}$ of $2.54 \pm 0.26 \mu \mathrm{g} / \mathrm{mL}$ and a $10 \%$ concentration of extract prevents virus adsorption onto the cell surface by $72.9 \pm 3.4 \%$ [29]. The blackcurrant extract also completely hold back the adsorption of IFV-AH3, IFV-AH1tam, and IFV-B [30]. 


\section{Japanese cherry fruits against PEDV}

The Japanese Cherry cultivars namely, Prunus yedoensis, $P$. sargentii, P. lannesiana, and $P$. cerasus have antiviral activity by inhibiting the infection cycle of PEDV [31]. Among these cultivars, the fruit extracts of $P$. cerasus exhibited significant antiviral activity by inhibiting $50 \%$ of the cytopathic effect against PEDV with very minimal concentration. The fruit extract may be used as dietary supplements and natural antiviral agents due to the presence of a rich amount of polyphenolic compounds.

\section{Almond skin against HSV-1 and HSV-2}

The almond [Prunus dulcis (Mill.) D.A. Webb, Rosaceae] skin extract blocks the entry of virion into the host cells (during HSV-1 lytic cycle) and prevented the spread of HSV-1 to neighbouring cells [32]. The almond skin extract also induced the cytokine production by activating proinflammatory host response for type 1 immunity, mononuclear cells, production of pro-inflammatory cytokines like IFN- $\alpha$, IFN- $\gamma$, tumor necrosis factor (TNF- $\alpha$ ), and IL-12. This process led to an improvement in peripheral blood mononuclear cells by eliciting Th1 and Th2 subsets which in turn decreases the HSV-2 replication in the host cells [33].

\section{Stone wood (bael) against CV-B3}

The Vero cell monolayers pretreated with $250 \mu \mathrm{g} / \mathrm{mL}$ of bael [Aegle marmelos (L.) Correa, Rutaceae] fruit extract reduces the CV-B3 virus titers, which signifying its effect on virus adsorption, penetration, and blocking of virus-specific receptor sites with no observable toxicity [34]. Further, diluted decoction (at 10\%) of bael fruit shows significant anti-rotaviral activity by decreasing the viral infectivity in MA-104 cells with the least cell toxicity [35].

\section{Apple and grape pomace against HSV-1 and HSV-2}

The extracts of apple and grape pomace are reported to possess antiviral activity against HSV-1 and 2. Methanolic extract of apple pomace (a by-product of cider-processing industries) prevents the viral replication at $1200 \mu \mathrm{g} / \mathrm{mL}$. This concentration can decrease the percentage of cytopathic effect by more than $90 \%$ by suppressing the replication of viruses [9]. The antiherpetic property of apple pomace in HSV-1 and HSV-2 may be due to the presence of a rich amount of flavonoids since apple pomace has a high amount of phenolic compounds with significant antioxidant activity [36]. Apple pomace extracts strongly inhibit the HSV-1 and HSV-2, however, its effect reduces as the time of inoculation is increased. This shows that the extract interferes with viral replication at the initial stages [37]. The extracts prevent $75 \%$ of virus binding at 300 and $700 \mu \mathrm{g} / \mathrm{mL}$ for HSV-1 and HSV-2 respectively and reduce the virus infectious titers $\leq 0.3 \log _{10}$ confirming its inability to directly inactivate extracellular virions.

The prominent phytochemicals like procyanidin $\mathrm{B} 2$ and flavonol quercitrin present in the apple pomace could be responsible for the antiviral activity of the extract [38]. The replication of HSV-1 and 2 replication is significantly reduced and complete prevention of infection is recorded at $1000 \mu \mathrm{g} / \mathrm{mL}$ with a reduced percentage of cytopathic effect by more than $90 \%$ [9]. From the above findings, it is suggested that the apple pomace could be a potential drug in treating herpetic diseases and could also be included in topical formulations in treating sexually acquired HSV infections. Grape pomace extracts are rich in bioactive phenolic compounds (polyphenols) and reported to have antioxidant, antimicrobial, antiviral, anticancer, and anti-inflammatory activities [39]. Aqueous pomace extract obtained from the red grape variety exhibits strong antiviral activity against the H5N1 virus by plaque infectivity reduction and this effect might be due to the presence of anthocyanins [40].

\section{Antiviral effect of fruit juices}

In addition to the potential antiviral activity of various fruit parts and their chemical constituents, fresh juices obtained from edible fruits, and beverages have significant antiviral properties. Fruit juices obtained from various edible fruits contain a variety of nutrients with rich amount of phytochemicals which have the potential to improve human health and reduce the risk of major chronic diseases [41]. Antiviral activity of blueberry, raspberry, strawberry, cranberry, plum, pomegranate, crab apple, grape, and peach fruit juices was tested against the HSV and enteric viruses [42].

The strawberry fruit juice at varying concentrations and $\mathrm{pH}$ exhibits a potent antiviral effect against CV-B5, echovirus 7, poliovirus-1, reovirus-1, and HSV [42]. They reported the antiviral activity of some plant-based compounds like ascorbic acid, chlorogenic acid, cyanin gallic acid, vanillin, malvin, and tannin acid against various virus strains, in which HSV and poliovirus were most sensitive for tannic acid. Of the 19 commercially available fruit juices and beverages studied for their antiviral activity against poliovirus, grape and apple juices are effective against the survival of poliovirus- 1 and this may due to the presence of polyphenols including tannins and related compounds in these two juices $[43,44]$.

The different varieties of commercial grape juices are found to inactivate several enteric viruses and HSV at both natural and neutral $\mathrm{pH}$ with a 1000 -fold reduction in infectivity of poliovirus [45]. This significant antiviral activity and infectivity rate of grape juice was achieved with gelatin $(1 \%)$, Tween $80(0.1 \%)$, polyvinyl pyrrolidone $(0.5 \%)$, and 
polyethylene glycol $(0.5 \%)$. The study demonstrated that grape juice displayed good stability which was influenced by the $\mathrm{pH}$ level, incubation period of poliovirus, and concentration of existing phytochemicals in the grape juice. However, fresh juices lose their potency rapidly during the storage (when kept for a longer duration or in cold storage) due to the oxidation of tannins which reduce their effectiveness for acting against the virus. However, fresh grape juice may be effective antiviral agents when the active components transit through the digestive tract [43].

Antiviral effect of commercial cranberry fruit juice on bacteriophage $\mathrm{T} 2$ and $\mathrm{T} 4$ shows loss of virus infectivity titers which are undetectable and the treatment of juice extract suspension inhibited haemagglutination of simian rotavirus SA-11 and its absorption and replication of phage T4 [46]. Cranberry fruit juice and proanthocyanidins isolated from cranberry fruits evaluated for foodborne viral surrogates like MNV-1, FCV-F9, MS2 bacteriophage, and $\phi X-174$ on the infectivity followed by virus reduction rate by plaque assays [47]. In which, FCV-F9 titers were decreased within $30 \mathrm{~min}$, MS2 titers were decreased after $1 \mathrm{~h}$ with cranberry juice extract and viral reduction occurred and more than $50 \%$ total reduction was noticed within the first 10 min of treatment.

Lipson et al. [48] compared the antiviral activity of cranberry cocktail juice, anthocyanins, proanthocyanidins, flavonol glycoside obtained from cranberry juice extracts and proanthocyanidins from grape juice extracts against reoviruses. Cranberry cocktail juice caused reovirus infectivity loss of $10 \%$ by dsRNA segments after $96 \mathrm{~h}$ of treatment. The mango fruit extract with $10^{-1}$ diluted concentration showed significant antiviral activity against the influenza virus $\mathrm{H} 9 \mathrm{~N} 2$ which is propagated on fatal calve kidney and chicken embryo fibroblast with limited cytotoxicity [49].

Blueberry juice and proanthocyanidins extracted from the fruits of blueberry are effective against the infectivity of $\mathrm{HAV}$, human norovirus surrogates (FCV-F9), and MNV-1 at different concentrations [50]. FCV-F9 titers are reduced to unnoticeable levels with 1 and $2 \mathrm{mg} / \mathrm{mL}$ of proanthocyanidins after $1 \mathrm{~h}$ and with blueberry juice after $3 \mathrm{~h}$; MNV-1 titers are reduced to unnoticeable levels after $3 \mathrm{~h}$ with 1,2 , and $5 \mathrm{mg} / \mathrm{mL}$ of proanthocyanidins and after $6 \mathrm{~h}$ with blueberry juice. HAV titers are reduced to unnoticeable levels after $30 \mathrm{~min}$ with 2 and $5 \mathrm{mg} / \mathrm{mL}$ of proanthocyanidins.

Nikolaeva-Glomb et al. [51] evaluated the antiviral activity of fruits of wild berries such as strawberry (Fragaria vesca, Rosaceae), raspberry (Rubus idaeus, Rosaceae), bilberry (Vaccinium myrtillus, Ericaceae), lingonberry (Vitis vitisidaea), and anthocyanin fractions from all these berries against the human pathogenic viruses like poliovirus-1, CV-B1, human respiratory syncytial virus A2 and influenza virus $\mathrm{A} / \mathrm{H} 3 \mathrm{~N} 2$ by virus cytopathic effect inhibition test. Of these, total extracts of all these berry fruits inhibit the replication of CV-B1 and influenza A virus with the highest degree of inhibition. Similarly, anthocyanin fractions of all the wild berries considerably inhibit the replication of influenza virus $\mathrm{A} / \mathrm{H} 3 \mathrm{~N} 2$. These wild berries could be potential candidates of antiviral agents.

Freshly squeezed orange juice is rich in nutrients and bioactive compounds including vitamin $\mathrm{C}$, carotenoids, and major citrus flavanones like hesperidin and naringin with a wide range of therapeutic properties [52]. Goncalves et al. [53] reported that the HCV infection leads to oxidative stress owing to the stimulation of cell metabolism with decreased activity of enzymes responsible for antioxidant property and increased the activity of liver enzymes like alanine transaminase and aspartate transaminase. When the HCV infected patients frequently allowed to drink the sweet orange juice for eight weeks revealed improvement in the concentration of antioxidants, lipid profile (Fig. 2), liver inflammatory markers, aspartate transaminase level, and these positive observations specify that the sweet orange juice could be a suitable food supplement or antiviral therapy for $\mathrm{HCV}$ patients because of the presence of a high amount of dietary antioxidant compounds with no observed toxicity [53].

\section{Conclusion}

The present review reveals that the edible fruits are a valuable source of antiviral therapeutics and further in-depth research on the development of antiviral drugs is in great demand. The basic feature of newly emerging viruses is their ability to develop resistance against the existing antiviral agents encourages the continuous search for developing effective antiviral drugs. The resistance of chronic infectious viral pathogens like HIV, HCV, IFV, and coronaviruses to the currently available antiviral drugs has led to the demand for a novel and effective antiviral strategies [54]. The review suggests the need and importance of the listed edible fruits that have been tested as prominent antivirals. Mango fruits act as immunomodulators by increasing white blood cell count, size of spleen and thymus, and possess possible immunomodulatory effect by the improved number of bone marrow hematopoietic cells and these properties may be due to the presence of rich in mangiferin [55]. Pomegranate, papaya, white mulberry, Chinese boxthorn, bitter orange, and European plum hold immunomodulatory property by boosting the immune response in the human body and could be included as a supplementary diet in the preventive measure to combat against COVID-19 [56].

The anticipated role of edible fruit extracts in the management of COVID-19 as evidenced by their efficacy against other viral diseases is shown in Fig. 2. It was evident that, the edible fruit extracts may directly damage the virus structure and inhibit the entry of viruses by disturbing the connections between viral spike proteins and host ACE-2 


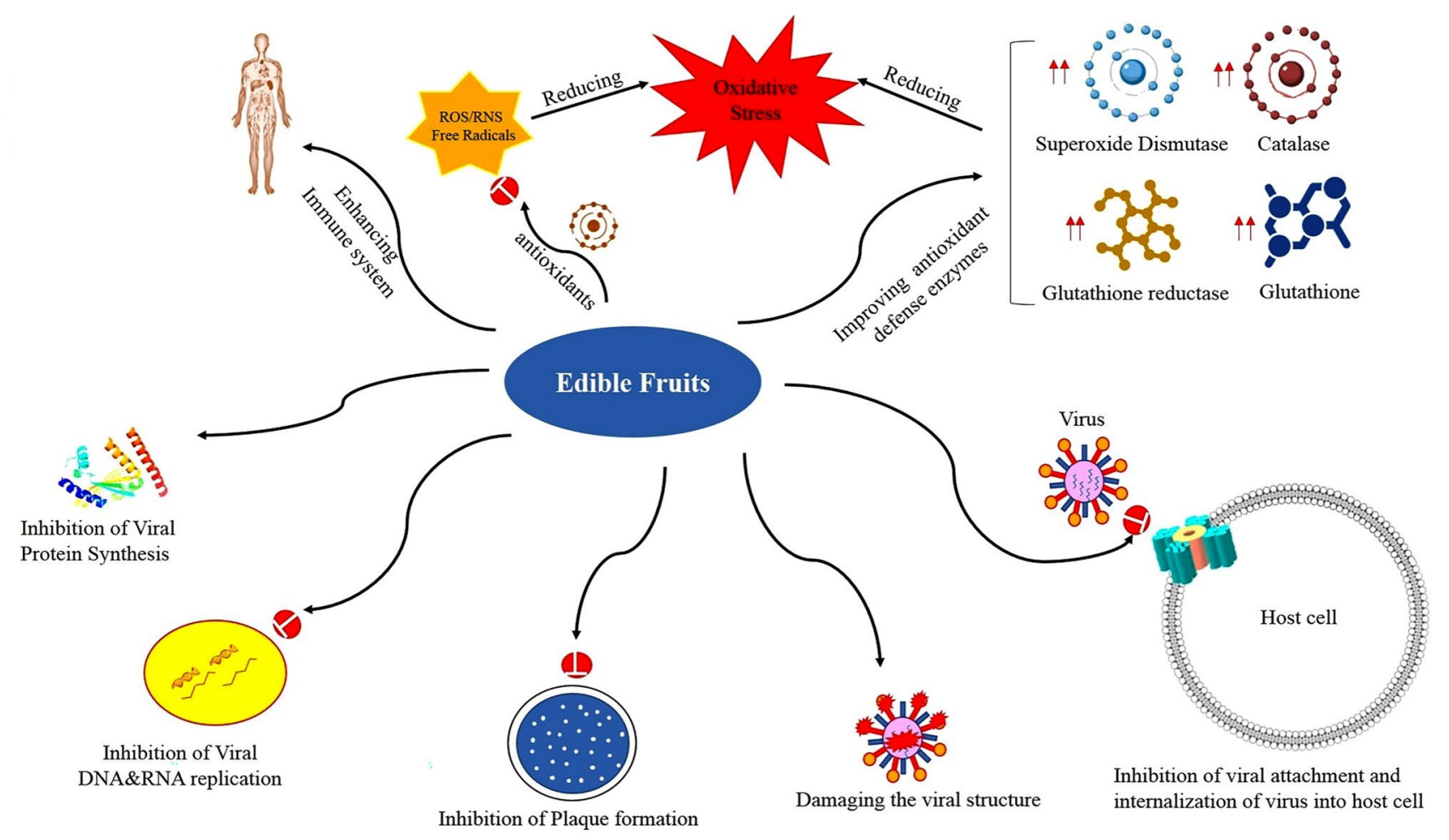

Fig. 2 Mechanism of edible fruit extracts and fruit juices in the prevention and treatment of various viral diseases. The inhibition symbol indicates the inhibitory property of fruit extract and the red arrow indicates the activation of antioxidants/immune cells in the host cell

receptors. Also, edible fruits and their extracts reduce oxidative damage by suppressing the ROS/RNS and free radicals during the COVID-19 infection. The ability of edible fruit extracts may enhance the immune system while also reducing oxidative stress in the host cell machinery, which supports to prevent viral invasion.

This review gathered the antiviral effect of edible fruits and their components in a single platform to facilitate further research in developing novel therapeutics to overcome the current as well as future pandemic situations. The global population is facing a severe health crisis and it is essential to bring an effective solution to combat COVID-19. The researchers around the world are trying to discover an effective approach to overcome this situation and the present analysis could help the scientific community to think about the use of edible fruits as possible drug candidates for the prevention and treatment of emerging coronaviruses. Taking into consideration of the invention of effective synthetic drugs is a lengthy process, trying with the existing medications with natural products is one of the prime choices. Though, well-designed pre-clinical and clinical trials are necessary to validate the effectiveness of edible fruits against SARS-CoV-2 infection with the existing significances against other viral pathogens.

In view of this, the present review highlighted the significance of edible fruits to block the virulence of various deadly viruses through their inhibitory action against the entry and replication of viral genetic makeup and proteins. As discussed in this review and other recent publications, a wide array of natural products from edible fruits have proven to be excellent drug candidates against IFV, DENV, polio, CHIKV, Zika, HIV, HSV, HCV, etc. Considering the antiviral property of edible fruits, it is strongly advocated that the addition of edible fruits and its products as supplements in daily diet could yield significant health benefits by strengthening the immune system against various infectious diseases including COVID-19.

Acknowledgements The corresponding author is grateful to the Science and Engineering Research Board (SERB), New Delhi for financial support through the Grant number EMR/2016/007164. Also, we are thankful to the anonymous reviewers who contributed significantly to improve the quality of this review.

Author contributions VPS, PM, VPS, and SP made literature collection, validation, formal analysis, and writing the original draft. VS involved in preparation of flowcharts and mechanism images. RM, SSG, and PM made the data curation, review, and editing. MA conceived the idea of this review, revised the manuscript, and supervised the whole writing process. All authors have read and approved the final version of this submission. 


\section{Declarations}

Conflict of interest The authors declare that there are no conflicts of interest with respect to research, authorship and publication of this review article.

\section{References}

1. N.A. Sagar, S. Pareek, S. Sharma, E.M. Yahia, M.G. Lobo, Compr. Rev. Food Sci. Food Saf. 17, 512 (2018)

2. I. Jantan, W. Ahmad, S.N.A. Bukhari, Front. Plant Sci. (2015). https://doi.org/10.3389/fpls.2015.00655

3. A. Saxena, A.S. Bawa, P.S. Raju, Food Chem. 115, 1443 (2009)

4. T.C. Wallace, R.L. Bailey, J.B. Blumberg, B. Burton-Freeman, C.O. Chen, K.M. Crowe-White, A. Drewnowski, S. Hooshmand, E. Johnson, R. Lewis, R. Murray, S.A. Shapses, D.D. Wang, Crit. Rev. Food Sci. Nutr. 60, 2174 (2020)

5. C.M. Galanakis, Trends Food Sci. Technol. 26, 68 (2012)

6. D.A. Hyson, Adv. Nutr. 6, 37 (2015)

7. J. Sun, Y.-F. Chu, X. Wu, R.H. Liu, J. Agric. Food Chem. 50, 7449 (2002)

8. D. Baxter, Occup. Med. (Chic. Ill) 57, 552 (2007)

9. B. Suárez, Á.L. Álvarez, Y.D. García, G. del Barrio, A.P. Lobo, F. Parra, Food Chem. 120, 339 (2010)

10. G. Nonaka, I. Nishioka, M. Nishizawa, T. Yamagishi, Y. Kashiwada, G.E. Dutschman, A.J. Bodner, R.E. Kilkuskie, Y.-C. Cheng, K.-H. Lee, J. Nat. Prod. 53, 587 (1990)

11. A.B. Howell, D.H. D'Souza, Evid.-Based Complement Med. Altern. (2013). https://doi.org/10.1155/2013/606212

12. X. Su, A.B. Howell, D.H. D'Souza, Food Microbiol. 27, 985 (2010)

13. A. Sundararajan, R. Ganapathy, L. Huan, J.R. Dunlap, R.J. Webby, G.J. Kotwal, M.Y. Sangster, Antiviral Res. 88, 1 (2010)

14. G.J. Kotwal, Vaccine 26, 3055 (2008)

15. M.T. Moradi, A. Karimi, M. Shahrani, L. Hashemi, M.S. GhaffariGoosheh, Avicenna J. Med. Biotechnol. 11, 285 (2019)

16. M. Haidari, M. Ali, S. Ward Casscells, M. Madjid, Phytomedicine 16, 1127 (2009)

17. A.R. Neurath, N. Strick, Y.Y. Li, A.K. Debnath, BMC Infect. Dis. 4, 1 (2004)

18. J. Arunkumar, S. Rajarajan, Microb. Pathog. 118, 301 (2018)

19. M. Moradi, A. Karimi, S. Alidadi, M. Gholami-Arjenaki, J. Chem. Pharm. Res. 7, 82 (2015)

20. M.T. Moradi, A. Karimi, Z. Lorigooini, B. Pourgheysar, S. Alidadi, L. Hashemi, Marmara Pharm. J. 21, 843 (2017)

21. D.M.J. Houston, J.J. Bugert, S.P. Denyer, C.M. Heard, PLoS ONE 12, $1(2017)$

22. H. Kim, M.S. Chung, Evid.-Based Complement Altern. Med. (2018). https://doi.org/10.1155/2018/2606583

23. M. Musarra-pizzo, R. Pennisi, I. Ben-amor, A. Smeriglio, G. Mandalari, M.T. Sciortino, Plants 9, 1 (2020)

24. R.J. Danaher, C. Wang, J. Dai, R.J. Mumper, C.S. Miller, Oral Surgery. Oral Med. Oral Pathol. Oral Radiol. Endodontol. 112, e31 (2011)

25. Y.M. Knox, T. Suzutani, I. Yosida, M. Azuma, Phytother. Res. 17, $120(2003)$

26. T. Suzutani, M. Ogasawara, I. Yoshida, M. Azuma, Y.M. Knox, Phytother. Res. 17, 609 (2003)

27. H. Sekizawa, K. Ikuta, K. Mizuta, S. Takechi, T. Suzutani, J. Sci. Food Agric. 93, 2239 (2013)

28. M. Oh, S.Y. Bae, J.-H. Lee, K.J. Cho, K.H. Kim, M.S. Chung, Foodborne Pathog. Dis. 9, 915 (2012)
29. K. Ikuta, K. Hashimoto, H. Kaneko, S. Mori, K. Ohashi, T. Suzutani, Microbiol. Immunol. 56, 805 (2012)

30. K. Ikuta, K. Mizuta, T. Suzutani, Fukushima J. Med. Sci. 59, 35 (2013)

31. H.-S. Yook, K.-H. Kim, J.-E. Park, H.-J. Shin, Am. J. Chin. Med. 38, 937 (2010)

32. C. Bisignano, G. Mandalari, A. Smeriglio, D. Trombetta, M.M. Pizzo, R. Pennisi, M.T. Sciortino, Viruses 9, 1 (2017)

33. A. Arena, C. Bisignano, G. Stassi, G. Mandalari, M.S.J. Wickham, G. Bisignano, Immunol. Lett. 132, 18 (2010)

34. L. Badam, S.S. Bedekar, K.B. Sonawane, S.P. Joshi, J. Commun. Dis. 34, 88 (2002)

35. S. Brijesh, P. Daswani, P. Tetali, N. Antia, T. Birdi, BMC Complement Altern. Med. 9, 1 (2009)

36. G. Ćetković, J. Čanadanović-Brunet, S. Djilas, S. Savatović, A. Mandić, V. Tumbas, Food Chem. 109, 340 (2008)

37. Á.L. Álvarez, S. Melón, K.P. Dalton, I. Nicieza, A. Roque, B. Suárez, F. Parra, J. Med. Food 15, 581 (2012)

38. T. De Bruyne, L. Pieters, M. Witvrouw, E. De Clercq, D. Vanden Berghe, A.J. Vlietinck, J. Nat. Prod. 62, 954 (1999)

39. C.M. Peixoto, M.I. Dias, M.J. Alves, R.C. Calhelha, L. Barros, S.P. Pinho, I.C.F.R. Ferreira, Food Chem. 253, 132 (2018)

40. A.A. Gaafar, M.S. Asker, M.A. Ali, Z.A. Salama, Jordan J. Biol. Sci. 12, 625 (2019)

41. C.H.S. Ruxton, E.J. Gardner, D. Walker, Int. J. Food Sci. Nutr. 57, 249 (2006)

42. J. Konowalchuk, J.I. Speirs, J. Food Sci. 41, 1013 (1976)

43. J. Konowalchuk, J.I. Speirs, Appl. Environ. Microbiol. 35, 1219 (1978)

44. J. Konowalchuk, J.I. Speirs, Appl. Environ. Microbiol. 36, 798 (1978)

45. J. Konowalchuk, J.I. Speirs, Appl. Environ. Microbiol. 32, 757 (1976)

46. S.M. Lipson, L. Sethi, P. Cohen, R.E. Gordon, I.P. Tan, A. Burdowski, G. Stotzky, Phytomedicine 14, 23 (2007)

47. X. Su, M.Y. Sangster, D.H. D'Souza, Foodborne Pathog. Dis. 7, $1473(2010)$

48. S.M. Lipson, P. Cohen, J. Zhou, A. Burdowski, G. Stotzky, Mol. Nutr. Food Res. 51, 752 (2007)

49. A.A.S. Al Rawi, H.S.H. Al Dulaimi, M.A.A. Al Rawi, J. Pure Appl. Microbiol. 13, 455 (2019)

50. S.S. Joshi, A.B. Howell, D.H. D’Souza, Food Environ. Virol. 8, $235(2016)$

51. L. Nikolaeva-Glomb, L. Mukova, N. Nikolova, I. Badjakov, I. Dincheva, V. Kondakova, L. Doumanova, A.S. Galabov, Nat. Prod. Commun. 9, 51 (2014)

52. A.A. Franke, R.V. Cooney, S.M. Henning, L.J. Custer, J. Agric. Food Chem. 53, 5170 (2005)

53. D. Gonçalves, C. Lima, P. Ferreira, P. Costa, A. Costa, W. Figueiredo, T. Cesar, Food Nutr. Res. 61, 1 (2017)

54. Z. Lou, Y. Sun, Z. Rao, Trends Pharmacol. Sci. 35, 86 (2014)

55. S. Shailajan, S. Menon, S. Kulkarni, B. Tiwari, Pharmacogn. Commun. 6, 137 (2016)

56. F. Yang, Y. Zhang, A. Tariq, X. Jiang, Z. Ahmed, Z. Zhihao, M. Idrees, A. Azizullah, M. Adnan, R.W. Bussmann, Phytother. Res. 34, 6770 (2020)

Publisher's Note Springer Nature remains neutral with regard to jurisdictional claims in published maps and institutional affiliations. 